\title{
ECONOMIA SOLIDÁRIA UM CAMPO DE ESTUDO EM CONSTRUÇÃO: ANÁLISE DA PRODUÇÃO CIENTÍFICA NACIONAL DE 2000 A 2015 SOLIDARITY ECONOMY A STUDY FIELD UNDER CONSTRUCTION:
}

ANALYSIS OF NATIONAL SCIENTIFIC PRODUCTION 2000 TO 2015

Rita de Cássia Trindade dos Santos' ${ }^{1}$ Bruna de Vargas Bianchim², Talita Gonçalves Posser ${ }^{3}$ e Vânia Medianeira Flores Costa ${ }^{4}$

RECEBIDO EM: 25/02/2017 | APROVADO EM: 05/03/2017

DOI: $10.5902 / 2317175825975$

\begin{abstract}
RESUMO
A expansão das iniciativas de economia solidária no Brasil é resultado de um processo orgânico de articulação que procura manter os empreendimentos econômicos solidários no mercado apesar de suas peculiaridades. Situar a discussão acerca da gestão dessas organizações faz-se importante no campo teórico dos estudos em administração, visto que as características de tais empreendimentos diferem-se, em partes, das empresas tradicionais. Assim, o presente estudo tem por objetivo analisar a produção científica brasileira sobre economia solidária e temas correlatos a partir das publicações na área de administração no período de 2000 a 2015. Para isso, realizou-se um estudo bibliométrico de abordagem quantitativa e qualitativa. A partir dos resultados obtidos concluiu-se que, quantitativamente, há um número progressivo de publicações no período analisado, com predominância dos estudos empíricos, de natureza exploratória e abordagem qualitativa cuja escolha dos objetos de pesquisa mostra uma tendência a favor de empreendimentos solidários, associações e cooperativas. Já sob a perspectiva qualitativa, os temas correlatos de maior incidência foram gestão social, autogestão, sustentabilidade e políticas públicas.
\end{abstract}

Palavras-chave: Economia Solidária; Gestão; Estudo Bibliométrico.

\footnotetext{
1 Acadêmica do curso de mestrado em Administração no Programa de Pós-Graduação em Administração da UFSM. E-mail: rita.santos0606@gmail.com.

2 Acadêmica do curso de mestrado em administração do Programa de Pós Graduação em Administração da UFSM. E-mail: bruna.bianchim@gmail.com.

3 Acadêmica do curso de graduação em Administração da UFSM. E-mail: talita.gposser@gmail.com.

4 Doutora em Administração. Professora associada do Departamento de Ciências Administrativas da Universidade Federal de Santa Maria. E-mail: vania.costa@ufsm.br.
} 
ECONOMIA SOLIDÁRIA UM CAMPO DE ESTUDO EM CONSTRUÇÃO:

ANÁLISE DA PRODUÇÃO CIENTÍFICA NACIONAL DE 2000 A 2015

\begin{abstract}
The expansion of solidarity economy initiatives in Brazil is the result of an organic process of articulation that seeks to keep economic enterprises in solidarity in the market despite their peculiarities. Placing the discussion about the management of these organizations is important in the theoretical field of management studies, since the characteristics of such ventures differ in part from traditional firms. Thus, the present study aims to analyze the Brazilian scientific production on solidarity economy and related topics from publications in the area of administration from 2000 to 2015. For this, a bibliometric study of quantitative and qualitative approach was carried out. From the obtained results it was concluded that, quantitatively, there is a progressive number of publications in the analyzed period with predominance of empirical studies, exploratory in nature and qualitative approach, whose choice of research objects shows a tendency in favor of joint ventures, associations and Cooperatives. Under the qualitative perspective, the correlated themes of higher incidence were social management, self-management, sustainability and public policies.
\end{abstract}

Keywords: Solidary Economy; Management; Bibliometric Study.

\title{
1 Introdução
}

A administração científica proposta por Frederick Taylor inicia sua trajetória impulsionada pelo contexto de revolução industrial buscando responder as demandas das organizações tradicionalmente estruturadas pela divisão entre trabalho e capital. Em meio a essa realidade, diferentes modos de produção e práticas organizacionais coexistiram como aquelas introduzidas por Robert Owen no início do século XIX, na famosa indústria têxtil em New Lanark.

Conforme Culti, Koyama e Trindade (2010), no Brasil, o modo de organização da produção, comercialização, finanças e consumo gerido por meio do trabalho associado, da cooperação e da autogestão são características típicas das organizações de Economia Solidária que engloba milhares de empreendimentos coletivos e redes de cooperação, entre outros. Lima (2001) constata em seu estudo sobre o tema que para alguns estudiosos tais iniciativas são utópicas e não possuem potencial de auto-sustentação embora reconheçam a busca pela consolidação de novas formas associativas de trabalho.

Passada a primeira década do Século XXI, as organizações de Economia Solidária permanecem no cenário brasileiro por meio da articulação coletiva de empreendimentos econômicos solidários, redes de produção e comercialização, cooperativismo popular, bancos comunitários, incubadoras universitárias, entre outros. O último mapeamento dos empreendimentos dessas atividades econômicas identificou 19.708 empreendimentos distribuídos entre 2.713 municípios brasileiros, entre o período de 2009 a 2013. Internacionalmente, o Instituto das Nações Unidas para a Pesquisa do Desenvolvimento Social (UNRISD) promoveu, em maio de 2013, em Genebra, com representação de diversos países, um amplo seminário para discussão sobre as potencialidades e desafios da Economia Solidária (MTE, 2014). 
A expansão das iniciativas de Economia Solidária é, portanto, resultado de um processo orgânico e organizado de articulação que busca se manter no mercado apesar de suas diferenças e peculiaridades de gestão. Para a ciência da Administração permeada predominantemente por estudos em empresas tradicionais, o campo dessa economia se mantém como uma fonte significativa de objetos empíricos e tem conquistado espaço no cenário acadêmico justamente pelos desafios consequentes de um outro modo de organização do trabalho (LIMA, 2001; SIMON, 2013; CALBINO E DE PAULA, 2014).

Assim, diante do processo de manutenção e disseminação de iniciativas de Economia Solidária, da relevância que a temática tem conquistado e dos desafios para a discussão desse fenômeno para a ciência da Administração, o presente estudo tem por objetivo analisar a produção científica brasileira sobre essa alternativa inovadora e temas correlatos a partir das publicações na área de administração no período de 2000 a 2015.

\section{Referencial teórico}

Nesta seção, apresentam-se breves considerações acerca da economia solidária e estudo bibliométrico.

\subsection{Economia solidária: origens e avanços.}

A concentração de renda, o desemprego, a degradação do meio ambiente e a redução do valor nominal dos salários são fatores que contribuem para o acirramento das desigualdades e da exclusão social. Para Singer e Souza (2003), esse cenário resultou na busca por novos modelos de produção, no Séc. XIX, sendo o pensamento cooperativista e o socialismo utópico os precursores da gestão diferenciada e democrática que resultarão na economia solidária. Dentre os principais idealizadores, encontram-se, por exemplo, Charles Fourier, Conde de Saint-Simon e Robert Owen (SINGER 2000). A economia solidária (ES) propõe uma nova forma de organização, sem basear-se na atuação do mercado ou do estado, questionando a relação entre a sociedade e a economia (FRANÇA FILHO, 2002).

No Brasil, o marco da institucionalização do movimento foi realizado pela Central Única dos Trabalhadores (CUT), em 1999, com a criação da Agência de Desenvolvimento Solidário (ADS). Tal iniciativa buscou organizar trabalhadores desempregados, movimentos sociais e setores da sociedade civil em prol das políticas públicas no campo da economia solidária como forma de fomentar e desenvolver, associados e cooperativados, como alternativa à exclusão social e geração de renda (GONÇALVES, 2012).

Desde então, a organização política avançou consideravelmente por meio de fóruns e redes. Em 2001, nos Fóruns Sociais Mundiais, constituiu-se o Grupo de Trabalho Brasileiro de Economia Solidária e I Plenária Nacional de Economia Solidária. As próximas conquistas nesse campo foram a criação da 
Secretaria Nacional de Economia Solidária (SENAES), o Conselho de Economia Solidária (CONAES) e o Fórum Brasileiro de Economia Solidária (SILVA, 2011). Segundo o autor, as conquistas desses espaços no cenário político garantiram a união e o fortalecimento de empreendimentos como a União das Cooperativas de Agricultura Familiar e Economia Solidária (UNICAFES), da União e Solidariedade de Cooperativas e Empreendimentos de Economia Social (UNISOL) e a implantação de Centros de Formação de Economia Solidária (CFES) para formação de agentes para o desenvolvimento local dentro dessas perspectivas. Tais ações fortalecem a proposta de Lei da Política Nacional de Desenvolvimento da Economia Solidária que tem por intuito o estabelecimento jurídico do movimento além do compromisso, por parte do estado nacional, em relação ao seu fomento (SILVA, 2011).

Segundo Guerra (2014) a autogestão, cooperação, identificação, trabalho emancipado, tomada de consciência do processo produtivo, cidadania, consumo consciente, desenvolvimento humano, igualdade, qualidade de vida e solidariedade representam uma síntese dos valores que sustentam o fenômeno da Economia Solidária. Nesta perspectiva, os empreendimentos solidários, visam atender demandas reais de uma população, ou seja, não atuam na lógica do lucro (FRANÇA FILHO, 2002). Ao mesmo tempo, esse modelo não opera fora da realidade capitalista, mas busca formas de alcançar o desenvolvimento econômico com mais autonomia para os membros, humanização do trabalho e é pautado em práticas sociais e ambientais sustentáveis (MENDONÇA, RUAS E COSTA, 2012). Sendo assim, a eficiência em organizações solidárias está pautada em aspectos subjetivos como a qualidade de vida e plena utilização do potencial das pessoas entrelaçadas por relações de solidariedade e com equidade (RUTKOWSKI, 2008). A falta dessa quantificação limita a comprovação da eficiência e da superioridade econômica dos empreendimentos solidários (TERREROS E GORRIZ, 2008).

As incertezas e desafios nesse campo dificultam as ações de pessoas que buscam fomentar a criação de novos empreendimentos solidários, e essas limitações repercutem na construção e definição teórica, que por vezes aparece como movimento social, ou refinamento da forma administrativa vigente ou ainda como uma nova configuração à gestão (ONUMA, MAFRA E MOREIRA, 2012). Mesmo assim, as organizações solidárias tem se mantido com significantes números de envolvidos em meio ao ambiente competitivo proposto pelo modelo de administração vigente, justificando os estudos nesse campo e do levantamento dos aspectos relacionados a ele.

\subsection{Estudo Bibliométrico}

Os estudos bibliométricos começaram a ser difundidos a partir dos anos 90 (Século XX) e, segundo Silva (2008), servem para organizar certas quantidades de informação, que de alguma forma poderiam permanecer desordenados e sem leitura, mesmo sendo considerados um material de qualidade pelos estudiosos. No século XXI, a bibliometria é vista como um meio para difundir a literatura sobre 
um tema específico divulgado pelos meios científicos, a partir de um levantamento feito com base na "performance da investigação", termo citado por Silva (2008).

Pritchard (1969, p. 348) definiu bibliometria como "a aplicação de métodos matemáticos e estatísticos a livros e outros meios de comunicação". De acordo com o autor, a bibliometria engloba todos os estudos que tentam quantificar os processos de comunicação escrita. Araújo (2002) destaca que mais recentemente o foco não está somente na mensuração, mas na compreensão contextualizada da produção científica e de seus autores, estabelecendo uma parceria entre as técnicas bibliométricas e abordagens teóricas. Segundo Pritchard (1969), as principais características da bibliometria são:

1. Identificar as tendências e crescimento do conhecimento com base em uma matéria

2. Estudar dispersão e obsolescências de certos assuntos científicos;

3. Medir impacto dos estudos publicados e as informações disseminadas no meio acadêmico;

4. Quantificar a cobertura das revistas científicas;

5. Identificar autores e instituições mais produtivos.

De acordo com Guedes e Borschiver (2005) a bibliometria possui várias leis e princípios empíricos que usam métodos matemáticos e estatísticos, que estabelecem diretrizes de busca e classificação na pesquisa científica sobre Ciência da Informação. São três as principais leis mais utilizadas: Bradford, Lotka e Zipf.

A Lei de Bradfort, também conhecida como Lei da Dispersão, sugere que na medida em que os primeiros artigos sobre um novo assunto são escritos, eles são submetidos a uma pequena seleção, por periódicos apropriados, e se aceitos, esses periódicos atraem mais e mais artigos, no decorrer do desenvolvimento da área de assunto. Se o assunto continua a se desenvolver, emerge eventualmente um núcleo de periódicos, que corresponde aos periódicos mais produtivos em termos de artigos, sobre o tal assunto (BROOKES, 1969).

A Lei de Lotka ou Lei dos Quadrados Inversos considera que alguns pesquisadores, supostamente de maior prestígio em uma determinada área do conhecimento, produzem mais, e muitos pesquisadores, supostamente de menor prestígio, produzem pouco. A relação entre o número de autores e o número de artigos publicados por estes, em qualquer área científica, segue a Lei do Inverso do Quadrado 1/n2. Quanto mais solidificada estiver uma ciência, maior será a probabilidade de seus autores produzirem múltiplos artigos, em dado período de tempo (Lotka, 1929; Guedes \& Borschiver, 2005).

A Lei de Zipf ou Lei do Mínimo Esforço permite estimar as frequências de ocorrência das palavras de um determinado texto científico e tecnológico e a região de concentração de termos de indexação, ou palavras-chave, que um pequeno grupo de palavras ocorre muitas vezes e um grande número de palavras é de pequena frequência de ocorrência. 
A aplicação dos estudos bibliométricos apresenta como principal vantagem a padronização de procedimentos, que facilitam a mensuração dos dados coletados. Esse tipo de estudo revela informações das produções científicas realizadas até o momento, dos aspectos importantes já tratados, agregando conhecimento para novas publicações, que buscam conhecer os assuntos ainda não explorados (MACHADO; BARBOSA; QUINTANA, 2011).

Com relação à estudos bibliométricos na temática de Economia Solidária foram identificadas três publicações. A pesquisa de Santos, Santos e Oliveira (2012) concentrou-se nos principais periódicos nacionais da área de administração, utilizando a classificação superior ao nível B2 do Sistema Qualis da Capes Coordenação de Aperfeiçoamento de Pessoal do Ensino Superior, considerando publicações entre o período do ano 2000 ao final do ano de 2010. O critério para a inclusão do artigo foi as ocorrências dos termos: economia solidária, economia social, associativismo, economia de comunhão, cooperativas sociais, social economy e solidarity economy. Os resultados foram classificados de acordo com o total e o percentual de artigos sobre terceiro setor por periódico, frequência das publicações de acordo com sua classificação, quantidade de artigos por ano, autoria e coautoria dos artigos publicados, artigos publicados por estado, as universidades e o número de artigos publicados em Economia solidária, metodologia adotada pelos trabalhos publicados e artigos por tema e ano de publicação.

Simon (2013) fez um levantamento sobre o que tem sido publicado a respeito do tema "Economia Solidária" no portal Scielo brasileiro, referência para o CNPq, delimitou-se a artigos publicados em periódicos da área de administração, classificados como A2 e B1 pelo Sistema Qualis Capes, e posteriormente a Análise Crítica dos Discursos apresentados referente à Economia Solidária. Botelho et al (2014) realizou uma revisão sistemática dos artigos publicados no EnANPAD entre os anos de 2004 e 2013. Para aprofundar a análise, realizou-se uma revisão integrativa da literatura,da identificação dos artigos da amostra, dos artigos publicados por ano, dos autores mais citados pelos artigos da amostra e temas recorrentes. Assim sendo, o estudo bibliométrico contribui para o levantamento, avaliação e análise da produção científica, sendo um tipo de pesquisa geralmente utilizada para se fazer um levantamento da quantidade e da qualidade de artigos sobre um tema que é considerado relevante para uma determinada área, contribuindo para a avaliação e análise da produção científica.

\section{Método}

No intuito de responder ao objetivo geral de analisar a produção científica brasileira sobre Economia Solidária e temas correlatos a partir das publicações na área de administração no período de 2000 a 2015, realizou-se uma pesquisa bibliométrica de abordagem quantitativa e qualitativa. Segundo Araújo (2006), o estudo bibliométrico é caracterizado pela quantificação, identificação, análise e descrição de padrões presentes na produção científica. 
Desse modo, realizou-se por meio de desk research o levantamento dos artigos científicos publicados nos eventos da Associação Nacional de Pós-Graduação e Pesquisa em Administração (ANPAD) e Scientific Periodicals Electronic Library (SPELL) entre os anos de 2000 e 2015 sobre Economia Solidária. Para a seleção dos artigos, foram definidos como critérios duas expressões "Economia Solidária", como um tema mais amplo de pesquisa e "Empreendimento Solidário" por sua caracterização e proximidade com as demandas administrativas.

A operacionalização dessa busca na base de dados SPELL ocorreu por meio das palavras-chave e título dos artigos. Sobre os anais dos eventos da ANPAD: o Encontro da Associação Nacional de Pós-Graduação e Pesquisa em Administração (ENANPAD), o Encontro de Administração Pública e Governança (EnAPG), o Encontro de Estudos Organizacionais (EnEO), o Encontro Nacional de Gestão de Pessoas e Relações de Trabalho (EnGPR), Encontro de Ensino e Pesquisa em Administração e Contabilidade (EnEPQ), Encontro de Marketing (EMA), Encontro de Administração da Informação (EnADI), Encontro de estudos em estratégia (3S) e o Simpósio de Gestão da Inovação Tecnológica.

Cabe destacar que a busca nos anais dos cinco últimos eventos citados anteriormente não encontrou resultados. Em relação aos demais, vale mencionar a exceção do ENANPAD que ocorre anualmente, o EnAPG, EnEO e EnGPR que ocorrem a cada dois anos, sendo que o primeiro iniciou em 2004, o segundo em 2000 e o terceiro em 2007. Apesar disso, optou-se pela permanência desses anais devido a proposta de investigação em todos eventos da ANPAD.

Esse processo resultou em um total de 122 publicações, das quais após a leitura foram excluídas duas por não se enquadrarem no escopo desse estudo, restando 120 válidas. A análise dos artigos selecionados foi efetuada a partir das abordagens quantitativa e qualitativa. Na primeira etapa, para análise dos dados quantitativos, procedeu-se a tipificação de publicação teórica ou empírica. Após isso, foi realizada a caracterização do perfil metodológico dos artigos empíricos adaptada de Hoppen e Meirelles (2005) e Sampaio e Perin (2006), cujas classificações versam sobre o tipo de abordagem da pesquisa, natureza, instrumento para coleta e análise dos dados. Além disso, incluiu-se uma apreciação dos objetos de análise. Nessa fase, os dados foram analisados por meio de estatísticas descritivas.

Já na segunda etapa, para análise dos dados qualitativos, após a leitura completa dos artigos selecionados realizou-se um mapeamento dos temas correlatos associados à Economia Solidária na produção científica. Objetivando-se, assim, identificar quais as principais articulações teóricas foram sendo realizadas dentro desse campo de estudo, agrupando-as em categorias. Nessa fase, os dados foram analisados por meio de análise de conteúdo e categorização a posteriori.

\section{Apresentação e discussão dos resultados}

Nesta seção apresenta-se a discussão dos resultados tanto da abordagem quantitativa quanto da qualitativa 
ECONOMIA SOLIDÁRIA UM CAMPO DE ESTUDO EM CONSTRUÇÃO:

ANÁLISE DA PRODUÇÃO CIENTÍFICA NACIONAL DE 2000 A 2015

4.1 Fonte da publicação, caracterização da pesquisa e principais autores no período analisado

Dentre as bases de dados pesquisadas, verificou-se que a maioria dos estudos sobre Economia Solidária estão publicadas no SPELL, no qual constam 77 artigos, já nos eventos da ANPAD em que houveram publicações, foram localizados apenas 43 artigos. Ademais, no período analisado, verifica-se que entre os anos de 2003 a 2005 não constavam publicações sobre o tema no SPELL, somente nos eventos da ANPAD, situação que se inverte a partir de 2010 em diante (Figura 1).

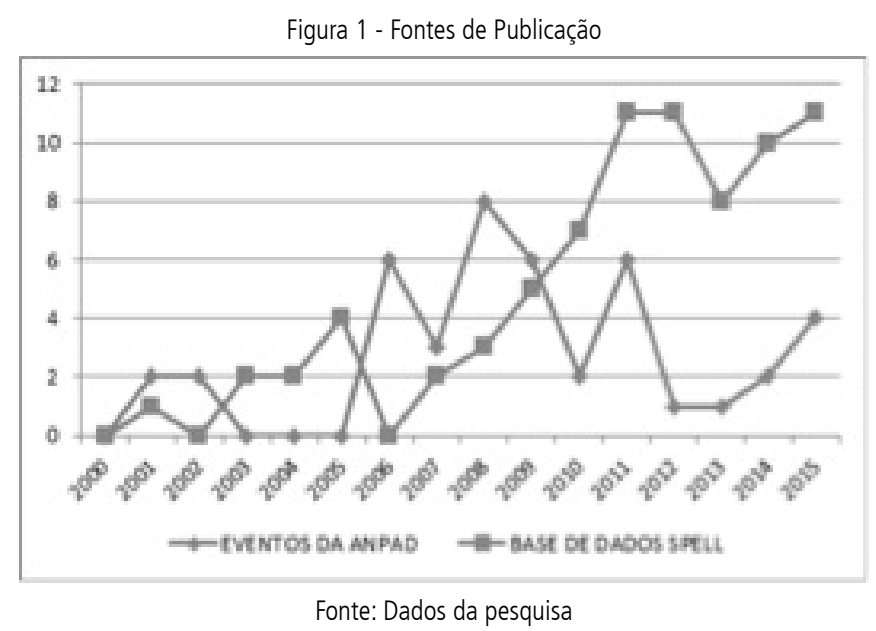

Sobre a caracterização da pesquisa constatou-se que do total dos artigos 75 são estudos empíricos e 45 são estudos teóricos. No período analisado, não houve publicações sobre o tema da Economia Solidária no ano 2000 nas bases pesquisadas. Entre os anos de 2001 à 2006 houve predominância dos estudos teóricos, a partir desse ano em diante há uma oscilação frente aos estudos empíricos, finalizando o período com uma tendência à ampliação destes. Tais resultados sinalizam uma produção científica na área da Economia Solidária em construção e discussão de conceitos que tende, ao longo do período, se deslocar para o campo prático de experimentação empírica (Figura 2). 
Figura 2: Tipos de Pesquisa

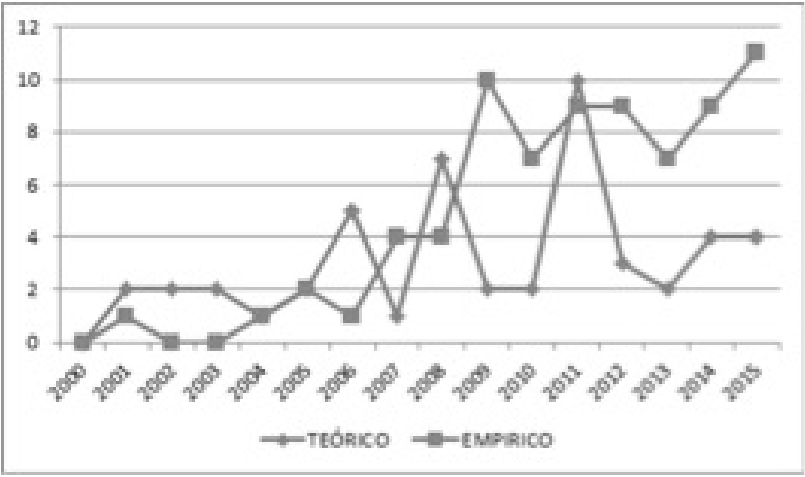

Fonte: Dados da pesquisa

No que tange a autoria, os 120 artigos analisados contemplam um total de 203 autores envolvidos, dentre os quais 152 autores publicaram apenas um artigo e 35 autores publicaram 2 artigos. Os principais autores, devido ao número de publicações, possuem entre 3 a 9 artigos. Pela variedade de autoria sobre o tema (Figura 3) constata-se que esse é um campo de estudos de interesse crescente, mas ainda pouco aprofundado embora já sinalize para alguns estudiosos profícuos.

Figura 3: Autores com maior número de publicações

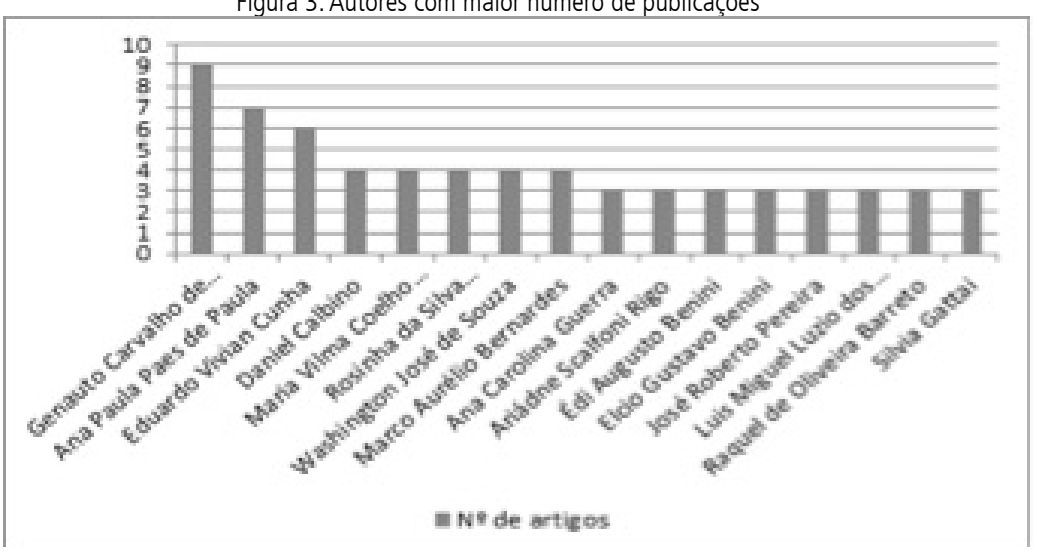

Fonte: Dados da pesquisa

Pelo exposto na Figura 3, três autores destacam-se na publicação nacional. Conforme dados da Plataforma Lattes, o autor Genauto Carvalho de França-Filho é docente da Universidade Federal da Bahia (UFBA), cujos estudos estão sob a ênfase das teorias organizacionais. A segunda autoria de maior destaque é a de Ana Paula Paes de Paula, docente na Universidade Federal de Minas Gerais (UFMG), atualmente coordenadora do Núcleo de Estudos de Gestão Dialógica (NEGD) e do Observatório de Práticas Participativas (OPP). Por fim, o terceiro autor é Eduardo Vivian Cunha, docente na Universidade Federal do Ceará (UFC), atuando nos cursos de Administração Pública, Administração e no Programa de Pós-Graduação em Desenvolvimento Regional Sustentável (Proder). 
ECONOMIA SOLIDÁRIA UM CAMPO DE ESTUDO EM CONSTRUÇÃO:

ANÁLISE DA PRODUÇÃO CIENTÍFICA NACIONAL DE 2000 A 2015

\subsection{Perfil metodológico das publicações sobre Economia Solidária}

Para essa seção, são considerados somente os 75 estudos empíricos visto que não cabem aos estudos teóricos as categorias analisadas para a identificação do perfil metodológico. Tendo presente que este estudo pretende um levantamento de publicações sobre Economia Solidária na área da administração, optou-se por identificar quais os objetos de análise dos estudos empíricos. Assim, verificou-se, conforme dados apresentados no Quadro 1, que os Empreendimentos Solidários representam 22,69 \% desse total, seguido de estudos com variados objetos de análise classificado como "Outros" que somam $18,66 \%$, o que chama atenção e parece indicar uma dispersão de experiências empíricas estudadas. As associações e indivíduos com percentual de $16 \%$ cada, cooperativas $14,66 \%$, incubadoras $6,66 \%$ e bancos comunitários $5,33 \%$.

\begin{tabular}{|c|c|c|}
\hline Quadro 1 - Objetos de análise & & \\
\hline OBJETO DE ANÁLISE & No ARTIGOS & \% \\
\hline Empreendimentos Solidários & 17 & 22,69 \\
\hline Outros & 14 & 18,66 \\
\hline Associações & 12 & 16 \\
\hline Individuos & 12 & 16 \\
\hline Cooperativas & 11 & 14,66 \\
\hline Incubadoras & 5 & 6,66 \\
\hline Bancos Comunitários & 4 & 5,33 \\
\hline
\end{tabular}

Fonte: Dados da pesquisa

Apesar da categoria "Outros" e "Indivíduos" terem apresentado um percentual significativa no total de artigos analisado, quando verificado em conjunto com os demais ao longo do período, percebe-se que o cenário muda. Conforme ilustrado na Figura 4, a partir do ano de 2012 em diante, percebe-se um decrescimento desses objetos de análise e uma tendência de crescimento de estudos em empreendimentos solidários, associações e cooperativas. Esse deslocamento parece sinalizar uma consolidação dessas organizações como espaços característicos da Economia Solidária.

Figura 4 - Objetos de análise no período estudado

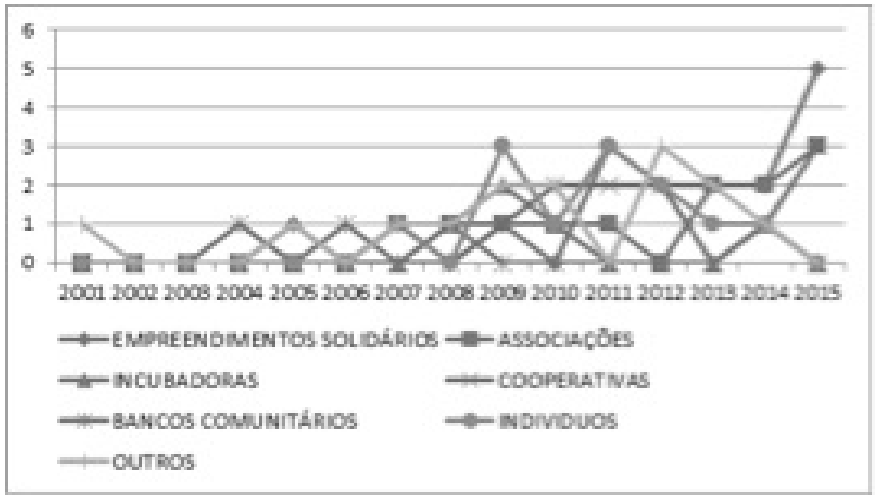

Fonte: Dados da pesquisa 
No que diz respeito a abordagem de pesquisa, 77, 34\% dos estudos empíricos sobre Economia Solidária no período são de abordagem qualitativa, $16 \%$ qualitativa e quantitativa e apenas $6,66 \%$ são de abordagem exclusivamente quantitativa (Quadro 2). Tal resultado parece corroborar com o entendimento de que o campo de estudos da Economia Solidária ainda permanece com uma vasta gama de possibilidades, especialmente em relação a complementaridade entre as diferentes abordagens.

Quadro 2 - Abordagem de Pesquisa

\begin{tabular}{|c|c|c|}
\hline ABORDAGEM & N2 ARTIGOS & $\%$ \\
\hline Qualitativa & 58 & 77,34 \\
\hline Qualitativa/Quantitativa & 12 & 16 \\
\hline Quantitativa & 5 & 6,66 \\
\hline
\end{tabular}

Fonte: Dados da pesquisa

Quando considerado o período estudado, confirma-se a predominância da abordagem qualitativa nas publicações, sendo ainda a única utilizada até o ano de 2006. Já a abordagem quantitativa é adotada nas publicações a partir de 2006 e a qualitativa e quantitativa no ano de 2007 conforme ilustrado na Figura 5. Atualmente persiste a predominância de estudos qualitativos embora o uso da abordagem quantitativa tenha crescido.

Figura 5 - Abordagens de pesquisa adotadas no período

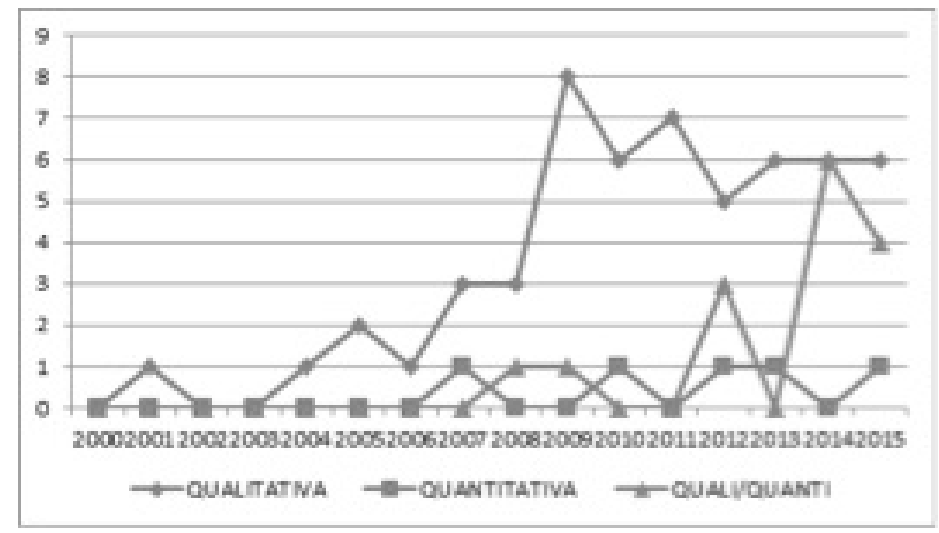

Fonte: Elaborada pelas autoras

Em relação à natureza da pesquisa, os dados contidos no Quadro 3 mostram que $36 \%$ das publicações são estudos exploratórios, o mesmo percentual tem os estudos descritivos e exploratórios, seguidos de $28 \%$ somente descritivos. Esse resultado indica um equilíbrio entre as diferentes naturezas de pesquisa. 
ECONOMIA SOLIDÁRIA UM CAMPO DE ESTUDO EM CONSTRUÇ̃̃O:

ANÁLISE DA PRODUÇÃO CIENTÍFICA NACIONAL DE 2000 A 2015

Quadro 3 - Natureza da pesquisa

\begin{tabular}{|l|c|c|}
\hline NATUREZA DA PESQUISA & NO ARTGOS & \% \\
\hline Exploratória & 27 & 36 \\
\hline Descritiva/Exploratória & 27 & 36 \\
\hline Descritiva & 21 & 28 \\
\hline
\end{tabular}

Fonte: Dados da pesquisa

O equilíbrio verificado quando considerado o total de publicações apresenta disparidades quando a análise é realizada a partir dos anos estudados. De acordo com o apresentado na Figura 6, até o ano de 2005 o campo de estudos da Economia Solidária contava somente com pesquisas de natureza exploratória, apesar das oscilações a partir do ano de 2006 as três passam as ser adotadas.

Figura 6 - Natureza da pesquisa das publicações no período

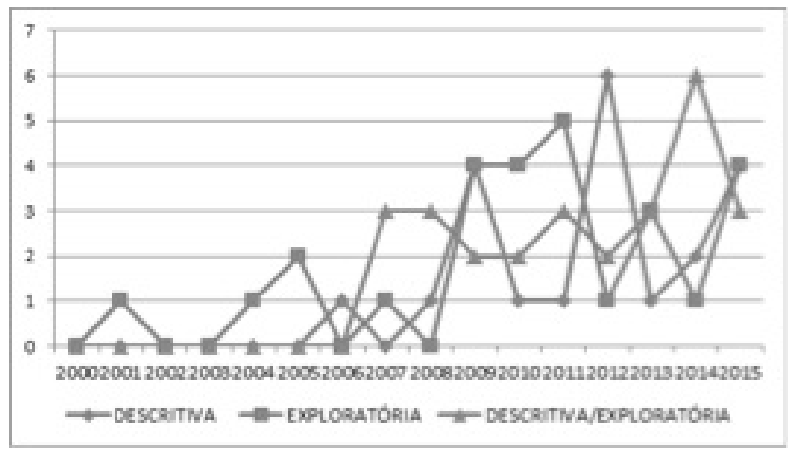

Fonte: Elaborada pelas autoras

Quando analisadas as técnicas utilizadas para coleta de dados, evidencia-se que as mais utilizadas são entrevistas, seguidas de pesquisa documental, observação, uso de questionário e outras variadas (Quadro 4). Cabe ressaltar que devido ao uso múltiplo de técnicas, estas foram classificadas por número de ocorrências.

Quadro 4 - Técnica para coleta de dados

\begin{tabular}{|l|c|}
\hline \multicolumn{1}{|c|}{ COLETA DE DADOS } & TOTAL DE OCORRENCIAS \\
\hline Entrevistas & 53 \\
\hline Pesquisa Documental & 29 \\
\hline Observaçăo & 25 \\
\hline Questionário & 11 \\
\hline Outros & 4 \\
\hline
\end{tabular}

Fonte: Dados da pesquisa

Quando analisada a distribuição no período estudado das técnicas utilizadas, confirma-se o predomínio do uso de entrevistas e pesquisa documental bem como a escassez do uso de questionários. Essa é uma constatação que vem ao encontro dos resultados já apresentados sobre a adoção limitada da abordagem quantitativa nas publicações. A Figura 7 evidencia a evolução no uso das diferentes técnicas. 
Figura 7 - Técnicas para coleta de dados utilizada no período

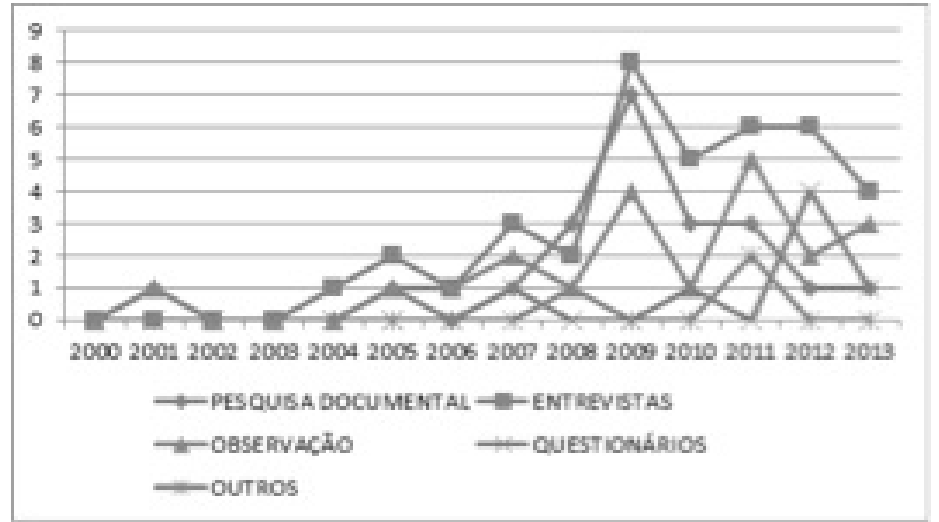

Fonte: Elaborada pelas autoras

Por fim, quanto a análise dos dados, $77,34 \%$ das publicações utilizaram análise de conteúdo, 12\% estatística descritiva ou testes estatísticos e 5,33\% análise de conteúdo e estatística descritiva e o mesmo percentual análise de discurso (Quadro 5). Desse modo, percebe-se que num período de 15 anos de publicação há uma nítida concentração na análise de conteúdo.

Quadro 5 - Análise dos dados

\begin{tabular}{|c|c|c|}
\hline ANALISE DOS DADOS & Ne ARTIGOS & $\%$ \\
\hline Analise de conteúdo & 58 & 77,34 \\
\hline Estatistica descritiva ou testes estatisticos & 9 & 12 \\
\hline Analise de conteúdo e estatistica descritiva & 4 & 5,33 \\
\hline Análise de discurso & 4 & 5,33 \\
\hline
\end{tabular}

Fonte: Dados da pesquisa

No decorrer do período estudado, confirma-se a predominância do uso da análise de conteúdo em praticamente todo o período, com exceção do ano de 2005. A análise por meio de estatística descritiva ou testes estatísticos passam a ser utilizadas periodicamente nas publicações somente a partir do ano de 2012, o mesmo ano em que os objetos de análise passam a ser predominantemente empreendimentos solidários, associações e cooperativas. Na Figura 8 apresentam-se os tipos de análise de dados adotados no período. 
ECONOMIA SOLIDÁRIA UM CAMPO DE ESTUDO EM CONSTRUÇ̃̃O:

ANÁLISE DA PRODUÇÃO CIENTÍFICA NACIONAL DE 2000 A 2015

Figura 8 - Análise de dados utilizada no período

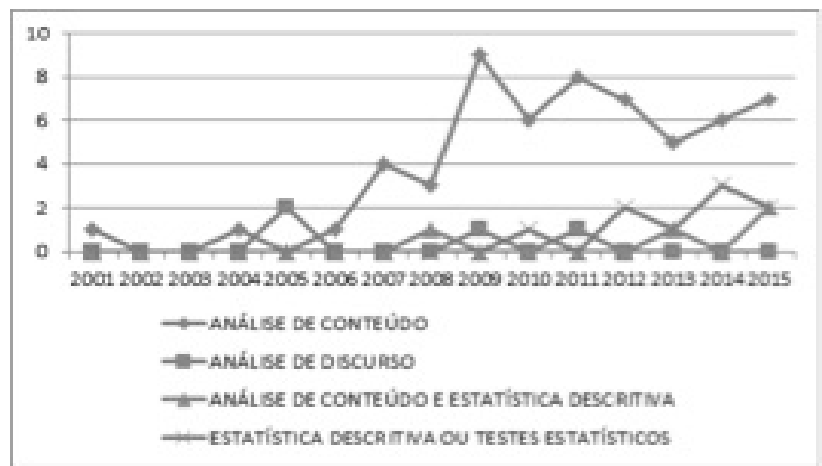

Fonte: Elaborada pelas autoras

\subsection{Panorama sobre os temas correlatos}

Nesta seção serão apresentados os temas correlatos à Economia solidária que foram encontrados durante a análise. Para a delineação dos mesmos, realizou-se a leitura interpretativa dos artigos de ambas as bases a fim de identificar as principais temáticas e seus enfoques no campo estudado. No Quadro 6, são descritas as categorias constituídas para a associação dos elementos em comum e registrada a ocorrência dos temas nos artigos publicados.

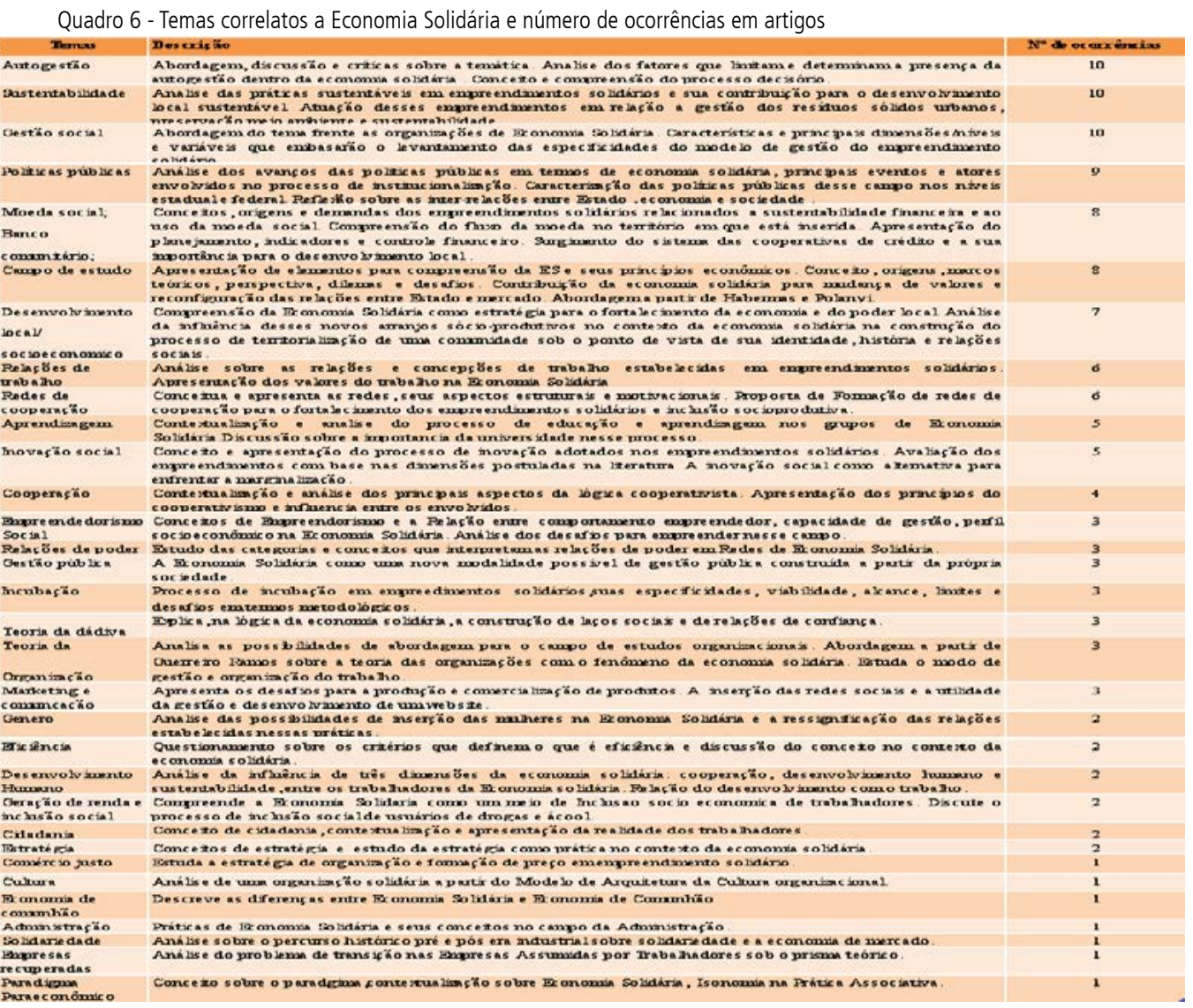

Fonte: elaborado pelas autoras 
Rita de Cássia Trindade dos Santos, Bruna de Vargas Bianchim, Talita Gonçalves Posser e Vânia Medianeira Flores Costa

Pelo exposto no Quadro 6, evidencia-se que alguns temas correlatos como autogestão, sustentabilidade, gestão social e políticas públicas destacaram-se por sua recorrência no período analisado presente num total de trinta e nove trabalhos. No que tange a autogestão como um valor inerente às organizações de economia solidárias, as publicações propõem a discussão em torno dos principais elementos e desafios enfrentados diante da lógica mercantil da economia. A sustentabilidade aparece sob a perspectiva do desenvolvimento regional sustentável tanto ambientalmente como socialmente aliada à cooperação e desenvolvimento humano. A gestão social é vista como uma abordagem necessária frente às peculiaridades dos empreendimentos solidários devido aos seus aspectos social, econômico e político de promoção da pessoa humana dentro do contexto organizacional. Já o tema políticas públicas vincula-se como uma estratégia de expansão dos empreendimentos com a efetiva participação do poder público no fomento às iniciativas populares.

Esses achados sinalizam que o campo de estudos da economia solidária, no que tange à gestão de suas organizações, está associado a abordagens distintas daquelas tratadas na literatura tradicional da administração. Tais características corroboram com a análise dos achados quantitativos deste estudo no sentido de que essa temática configura-se como um campo ainda em construção na literatura cuja definição abrange um conjunto de conceitos que vem ao encontro de suas características peculiares.

\section{Considerações finais}

O presente estudo teve por objetivo analisar a produção científica brasileira sobre economia solidária e temas correlatos a partir das publicações na área de administração no período de 2000 a 2015. Para isso realizou-se um levantamento de artigos científicos sobre o tema nos eventos da Associação Nacional de Pós-Graduação e Pesquisa em Administração (ANPAD) e no Scientific Periodicals Electronic Library (SPELL).

No total, foram analisados 120 artigos cuja maioria (77 artigos) foi publicada na base SPELL. Ao averiguar a relação entre a obra e autoria constatou-se que o autor, Genauto Carvalho de França Filho é detentor do maior número de publicações no período estudado. No que tange a caracterização da pesquisa houve predominância dos estudos empíricos, de natureza exploratória e abordagem qualitativa com utilização de entrevistas como instrumento de coleta de dados. A técnica análise de conteúdo foi a mais utilizada para exploração dos dados e como objeto de estudo os empreendimentos solidários. Contudo, os dados quantitativos mostraram que, principalmente a partir do ano de 2012, o foco dos estudos passou a ter como objeto de pesquisa não só essas iniciativas, mas também associações e cooperativas, bem como houve um aumento da diversidade de instrumentos de pesquisa e técnicas para análise de dados, o que aponta para uma diversidade metodológica, aspecto importante para a qualidade dos estudos. 
ECONOMIA SOLIDÁRIA UM CAMPO DE ESTUDO EM CONSTRUÇ̃̃O:

ANÁLISE DA PRODUÇÃO CIENTÍFICA NACIONAL DE 2000 A 2015

Portanto, a partir dos resultados obtidos, conclui-se que o tema da economia solidária na área da administração tem sido estudado predominantemente por meio de estudos exploratórios, o que indica um campo de estudo em construção teórica. Tal constatação também é evidenciada na análise qualitativa dos trabalhos publicados no período, na qual os temas correlatos de maior incidência foram gestão social, autogestão, sustentabilidade e políticas públicas, indicando um universo de conceitos próprios ao fenômeno das organizações de economia solidária e as especificidades que envolvem a gestão. Verificou-se, portanto, que o conhecimento científico sobre o fenômeno pesquisado encontra-se em fase de amadurecimento metodológico permanecendo como um campo aberto para futuras investigações que dêem continuidade a trajetória de pesquisas.

Embora a presente pesquisa tenha identificado aspectos gerais da produção científica sobre a economia solidária no Brasil, dentre as limitações do estudo estão as restrições impostas pelo uso de bases específicas para análise que poderiam ser ampliadas e a profundidade insuficiente das análises dos temas correlatos. Sugere-se, para futuros estudos, a ampliação da base de dados dessa pesquisa, mapeando também a produção em periódicos de outras áreas próximas ao tema, como economia, ciências sociais e serviço social, além da comparação da produção brasileira e internacional.

\section{Referências}

ARAÚJO, C. A. Bibliometria: evolução histórica e questões atuais. Em Questão, v.12, n.1, p. 11-32, 2002.

BOTELHO L.L.R; WUERGES, A.E; THIELE J.M.; MACEDO, M.; TRINDADE E.P. Revisão Integrativa sobre o tema da Economia Solidária publicados no Enanpad entre 2004 E 2013. International Knowledge Engineering and Management, Florianópolis, v.3, n.7, p.171-195, nov./fev, 2015

CULTI, M N.; KOYAMA, M. A. H.; TRINDADE, M. Economia Solidária no Brasil: tipologia dos empreendimentos solidários. São Paulo: Todos os Bichos, 2010

BROOKES, B. C. Bradford's law and the bibliography of science. Nature, v.224, p.953-956, 1969.

CALBINO, D.; DE PAULA, A. P. P. Para uma discussão da eficiência na Economia Solidária: Algumas implicações teóricas e empíricas. In: ENCONTRO ANUAL DA ANPAD, 36., 2014, Rio de Janeiro. Anais... Rio de Janeiro: ANPAD, 2014

FÓRUM BRASILEIRO DE ECONOMIA SOLIDÁRIA. Sobre o FBES, s/d. Disponível em http://www.fbes.org.br. Acesso em 10 jun. 2016

FRANÇA FILHO, G. A perspectiva da economia solidária. In: FISCHER, T. (Org.). Gestão do desenvolvimento e poderes locais: marcos teóricos e avaliação. Salvador: Casa da Qualidade, 2002.

GONÇALVES, A. F. Economía(s) solidaria(s) y políticas públicas en brasil. Gestão \& Conexões Management and Connections Journal, v. 1, n. 1, p. 44-54, jul./dez, 2012.

GUEDES, V. L. S; BORSCHIVER, S. Bibliometria: uma ferramenta estatística para a gestão da informação e do conhecimento em sistemas de informação, de comunicação e de avaliação científica e tecnológica. In: ENCONTRO NACIONAL DE CIÊNCIA DA INFORMAÇÃO, 6, 2005, Salvador. Anais. Salvador, p. 1-18, 2005 
GUERRA, A. C. Os valores da economia solidária e os valores do trabalho: um estudo em empreendimentos econômicos solidários. Belo Horizonte, 2014. Tese (Doutorado em Administração) - Faculdade de Ciências Econômicas da Universidade Federal de Minas Gerais.

LIMA, A. L. M. C. O. Fenômeno da Economia Solidária: Reflexões em um Campo de Estudo Controverso. In: ENCONTRO ANUAL DA ANPAD, 25. 2001, São Paulo. Anais... Campinas: ANPAD, 2001

MENDONÇA, J.C. A.; RUAS, R.; COSTA, G.P. Estudo da implantação de uma fábrica de sabão ecológico segundo os princípios socio-ambientais. Revista de Administração da UNIMEP. v.10, n.3, set./dez., 2012.

MINISTÉRIO DO TRABALHO E EMPREGO. Texto de referência Contextualização e Balanço Nacional. In: Conferência Nacional de Economia Solidária, 3. 2014

ONUMA, F.M.S; MAFRA, F.L.N; MOREIRA, L.B. Autogestão e subjetividade: interfaces e desafios na visão de especialistas da ANTEAG, UNISOL e UNITRABALHO. Cadernos EBAPE.BR, v. 10, n. 1, p. 65-81. Rio de Janeiro, Mar. 2012

PRITCHARD, A. Statistical bibliography or bibliometrics? Journal of Documentation, v.25, n. 4, p. 348-349, 1969.

SANTOS, L.M.L; SANTOS, L. M; OLIVEIRA, B.C.S.C.M. Economia solidária no Brasil: um estudo bibliométrico em períódicos de administração da última década. Revista Facesi, v.4, n.1, 2012.

SILVA, José Miguel Pereira da Silva. O estado-da-arte da literatura em economia e gestão da inovação e tecnologia: um estudo bibliométrico. Porto, 2008. Dissertação (Mestrado em Inovação e Empreendedorismo Tecnológico). Faculdade de Engenharia, Universidade do Porto.

SILVA, R. M. A. Políticas públicas de economia solidária: avanços, desafios e perspectivas. Revista Diálogo, n.18, p. 53-76, jan./jun., 2011.

SIMON, V. S. P. Análise crítica do discurso sobre economia solidária nas publicações da área de Administração. In: ENCONTRO ANUAL DA ANPAD, 37., 2013, Rio de Janeiro. Anais... Rio de Janeiro: ANPAD, 2013

SINGER, P. Incubadoras universitárias de cooperativas: um relato a partir da experiência da USP. In: SINGER P.; SOUZA, A. (Org.). A economia solidária no Brasil: autogestão como resposta ao desemprego. São Paulo: Cortez, 2000. p. 123-133.

SINGER, P. Introdução à economia solidária. São Paulo: Fundação Perseu Abramo; 2002.

; SOUZA A. A economia solidária no Brasil: a autogestão como resposta ao

desemprego. São Paulo, Contexto, 2003.

RUTKOWSKI, J. Sustentabilidade de empreendimentos econômicos: uma abordagem na Engenharia de Produção. São Carlos, 2008. Tese (Doutorado em Engenharia de Produção) - Universidade Federal de São Carlos.

TERREROS, I. S.; GORRIZ, C. G. Empresa cooperativa vs. capitalista. ¿Afecta la forma de gobierno a la eficiencia productiva?. In: Revista Europea de Dirección y Economía de la Empresa, v. 17, n. 3, p. 133-144, 2008. 